\title{
El trabajo colaborativo, una didáctica para educar en entornos rurales
}

\section{Collaborative work, a didactics to educate in rural environments}

Elvia patricia Arango Zuleta ${ }^{1}$

\begin{abstract}
Resumen
En este estudio ${ }^{2}$ se corroboraron las contribuciones del trabajo colaborativo a la formación de docentes del sector rural, y se identificaron relaciones entre la producción textual de estudiantes de educación básica en Centros Educativos Rurales -CER-e Instituciones Educativas Rurales -IER-y las metodologías de trabajo escolar utilizadas por sus docentes, 48 estudiantes de Licenciatura en Educación Básica con énfasis en Humanidades y Lengua Castellana, en dos municipios de Antioquia. La investigaciónacción-participación promovió la autorreflexión de los estudiantes de Licenciatura y permitió establecer acuerdos respecto a principios y criterios para realizar el acompañamiento, el seguimiento y la evaluación de la práctica. A partir de la práctica, las aptitudes docentes de los estudiantes de Licenciatura presentaron cambios, reflejados en la búsqueda de alternativas para promover la escritura de textos en estudiantes de ciclos de la básica. De este ejercicio se desprende que las finalidades y los retos del proceso de formación se concretan en la búsqueda y el acceso a oportunidades sociales
\end{abstract}

Palabras clave: Didáctica, Metodologías de trabajo, Producción textual, Trabajo colaborativo.

Docente de la facultad de educación Universidad de Medellín.

Investigación denominada La producción textual con estudiantes que interactúan en escenarios rurales, una construcción cotidiana. 


\section{Abstract}

In this paper, collaborative work contributions to teacher formation in rural sectors were corroborated, as well as relationships between primary education students' textual production from Rural Educational Centers - CER — and Rural Educational Institutions — IER —, and school work methodologies deployed by their teachers. Those teachers were 48 students from the Humanities and Spanish Language Primary Education Teaching program, in two Antioquia municipalities. Participation-action-research promoted self-reflection among teaching students, and allowed for establishing agreements concerning principles and criteria to follow-up and evaluate their own practice. Based on that practice, students' teaching skills showed shome changes, which were reflected in the quest for alternatives to promote text writing among students in primary education. This exercise reflects itself in the goals and challenges of the teaching formation process, which is actualized in the search for and the access to social opportunities.

Keywords: Didactic, work methodologies, textual production, collaborative work.

\section{Introducción}

Entre el semestre 01 de 2007 y el semestre 01 de 2008 se ejecutó la investigación La producción textual con estudiantes que interactúan en escenarios rurales, una construcción cotidiana, articulada a la práctica investigativa ${ }^{2}$ de estudiantes de Licenciatura en Educación Básica con énfasis en Humanidades y Lengua Castellana. Estos estudiantes a la vez se desempeñaban como docentes de educación básica en Centros Educativos Rurales -CER-e Instituciones Educativas Rurales -IER- de Urrao y Fredonia, al suroeste de Antioquia.

La interpretación lograda hasta entonces en la investigación agotaba las posibilidades de identificar relaciones entre la producción textual de estudiantes de educación básica en CER e IER y las metodologías de trabajo utilizadas por sus docentes, pues, por una parte se carecía de acciones que testimoniaran el protagonismo de unos y otros, y por otra, era interés de los docentes asesores de práctica ${ }^{3}$, proveer herramientas útiles para transformar la realidad educativa. Las inquietudes respecto a las metodologías utilizadas por los docentes en las instituciones de básica y la dinámica del trabajo, dieron curso a la participación-acción dentro de este ejercicio.

La preparación y cualificación de docentes para la formación de estudiantes de educación básica, provocó por un lado, la búsqueda y utilización de un enfoque que propiciara el despliegue de sus potencialidades sin abandonar el contexto, y por otro, la búsqueda de estrategias que movilizaran la aprehensión de herramientas requeridas para conocer con amplitud, profundidad y complejidad, lo particular y relacional del saber pedagógico-saber específico y la formación en investigación. Ambos elementos convergieron en una perspectiva pedagógica sociocultural.

Los escenarios laborales de los estudiantes de Licenciatura y aquellos donde transcurre el Programa académico, contaron con distintos mecanismos y recursos para el desarrollo

Según el Manual de prácticas de las Licenciaturas en Educación del Tecnológico de Antioquia Institución Universitaria, existen tres modalidades de práctica: Interinstitucional, Investigativa y Emprendimiento.

3 Los asesores de práctica son tres docentes quienes simultáneamente son los investigadores. 
de contenidos, entre estos, el diálogo, el debate y la Web, conjuntados en la expresión encuentro. Durante las sesiones de seminario, la exposición de vivencias dentro del CER o la IER, unida al conocimiento de algunos lugares de trabajo, indicó la importancia de identificar e implementar alternativas metodológicas que desde la educación propendan por el desarrollo autónomo, la apropiación y multiplicación de conocimientos y su puesta en escena para la transformación social.

Los logros obtenidos por los estudiantes dentro de Fredonia y Urrao presentan diferencias y coincidencias; las primeras están dominadas especialmente por el entorno sociocultural y las segundas por el despliegue de habilidades cognitivas. En ambos casos el procesamiento de información logrado por los estudiantes de Licenciatura se refleja en los estudiantes de educación básica.

\section{Metodología}

En el segundo semestre de 2007 la marcha de la investigación La producción de textos en escenarios rurales, una construcción cotidiana, realizada a partir de la práctica investigativa de los estudiantes de Licenciatura en Educación Básica con énfasis en Humanidades y Lengua Castellana, en Fredonia y Urrao, Antioquia, movía en los investigadores inquietudes identificadas el semestre académico inmediatamente anterior, referidas a las metodologías de los docentes del sector rural para llevar a cabo el trabajo escolar. La población fue 62 estudiantes de ambos municipios de los cuales 48 constituyeron la muestra.
Fueron criterios para la muestra: ser normalista superior graduado, estar matriculado en la Licenciatura, ser docente de CER o IER, y de no ser así, realizar la práctica en una de tales instituciones. De los 48 estudiantes, 46 eran a la vez directores y docentes de Escuela Nueva, de ellos 10 trabajaron con grados cuarto y quinto mientras la mayoría lo hizo con los grados de primero a tercero; otros dos docentes trabajaron con el total de estudiantes bajo su responsabilidad en el Sistema de Aprendizaje Tutorial -SAT-. El promedio de estudiantes por grupo fue 17 en primaria y 14 en secundaria.

Las conversaciones, los ejemplos y testimonios de los docentes en profesionalización ${ }^{4}$ al igual que sus diarios diligenciados durante la práctica, expresaban incoherencias entre la puesta en escena de los principios de Escuela Nueva y las orientaciones dadas a los estudiantes de los ciclos de básica para realizar diferentes actividades, sin embargo, aquellos sólo señalaban desmotivación, poco compromiso y desinterés de los estudiantes de educación básica frente al estudio, causal del bajo rendimiento, la incomprensión de lectura, la renuencia a la escritura y la falta de ortografía.

La puesta en común de las inquietudes surgidas, los lugares de trabajo distanciados entre sí, la aceptación de que el conocimiento se construye, afianza, complejiza y avanza en comunidad, y el aprovechamiento de los recursos del entorno para el trabajo pedagógico, fueron conjugados para plantear y establecer acuerdos respecto a la búsqueda e implementación de estrategias que contribuyeran a la formación profesional, pudieran ser implementadas en los Centros Educativos Rurales -CER-y las Instituciones Educativas Rurales -IER- e hicieran efectivos los alcances de la práctica.

Denominados así al interior del Tecnológico de Antioquia, porque de acuerdo con el sistema educativo colombiano, son graduados como normalistas superiores que culminan después su formación profesional. 
Las situaciones identificadas llevaron a los estudiantes de ambos municipios a agruparse según las veredas en las cuales estaban ubicados, de modo que varias actividades de la práctica, la formación profesional y el trabajo en el CER o la IER pasaban por su discusión y elaboración antes de ponerlas en escena, redimensionarlas, hacer registro o comunicarlas. Las características de los grupos fueron distintas al igual que sus búsquedas y las estrategias utilizadas, sin embargo tuvieron principios y criterios de trabajo comunes.

La materialización de encuentros entre los estudiantes y de estos con los docentes puso en evidencia asuntos particulares -ideas, conceptos y significaciones que redundan en actitudes y comportamientos condicionados: 'así me enseñaron y así lo sé hacer', 'eso me embiste', 'nunca me imaginé ante un computador'y comunes - posturas y comportamientos generalizados que particularizan rasgos culturales dentro de los entornos rurales: 'si manejamos el computador tendremos mejores ideas...', '(...) también para buscar financiación para la escuela'paulatinamente modificados sin sufrir cambios radicales ni llegar a desmontarse.

Sentirse parte de los grupos, las comunidades y el entorno, alimenta el sentido de pertenencia de los docentes en profesionalización hacia el sector rural, enriquece el acervo, favorece la visibilización de saberes y posibilita compartir inquietudes, miradas y búsqueda de solución a situaciones problemáticas o de interés común. Este proceso se caracteriza por sinergias que permiten a los docentes realizar de manera consciente y libre, actividades intelectuales, físicas y experimentales, para compartir opiniones e ideas respecto a asuntos cotidianos que sistemáticamente aportan a sus conocimientos para entender-se o asimilarse, conforme a su ser y saber.
Las agrupaciones antes nombradas son distintas pero no excluyentes. Por definición, un grupo alude al conjunto de personas que comparten valores, comportamientos y creencias o a elementos con atributos semejantes; la comunidad es el conjunto de personas situadas geográficamente, dotadas de autonomía legislativa, competencias ejecutivas, administración y con sus propios representantes, vinculada por acuerdos políticos o intereses comunes y económicos. El entorno es el lugar o espacio físico, caracterizado por la circulación de contenidos, la coexistencia de factores internos y externos que afectan la vida humana y las influencias derivadas de las actuaciones $\mathrm{y}$ funciones de quienes conforman las comunidades.

La aproximación de los estudiantes de Licenciatura a la producción textual de los estudiantes de básica como situación problema, la identificación de causas de ese problema, de los factores emocionales, familiares, cognitivos o educativos concurrentes y de las interrelaciones e implicaciones de esos aspectos en la escolaridad, moviliza la búsqueda de soluciones e introduce en la investigación-acción con las variantes que pueda tomar, esto último, atendiendo a que es un término genérico utilizado con diferentes usos y sentidos, sin criterios precisos para delimitar las metodologías que la reclaman, de las cuales se vale en búsqueda de la reunificación epistemológica de la teoría y la práctica o del mejoramiento del sistema educativo y social: Albert (2006), Carr (1996) y Latorre (2003).

Según diferentes discursos, la investigación-acción es relacionada con procesos autoevaluativos, de autorreflexión y metacognición; es un concepto que ha "ido cambiando con el tiempo y especialmente su significado, aparece vinculado al contexto sociocultural que envuelve al investigador" (Albert Gómez, 2006: 221). Es 
una característica que los asuntos problemáticos del entorno sean abordados por las personas conformadas en grupo, quienes a medida que deliberan, discuten, proponen y toman decisiones, hacen de la autocriticidad un medio y un fin para formarse en la autonomía y la corresponsabilidad.

En la formación profesional, la investigaciónacción-educación alude a "los (...) profesores como investigadores (...) y su relación con el saber educativo,(...) y el desarrollo del conocimiento profesional" (Elliot, 2000: 85); “(...) La enseñanza y la investigación se plantean como actividades independientes, mientras que, (...) la reflexión y la acción no son sino dos aspectos de un único proceso (Elliott, 2000: 27) "la investigación del profesorado aparece en los textos de investigación educativa con diferentes expresiones (...) que designan modelos de investigación con cierta especificidad, pero que se consideran expresiones intercambiables" (Latorre, 2003:23) e indisolubles en la práctica. Así lo vivieron los 48 estudiantes de la Licenciatura.

La conformación de grupos tuvo un carácter cooperativo y otro colaborativo. El primero se expresó al comienzo de la implementación metodológica cuando de manera espontánea al interior de cada grupo alguien tomaba el liderazgo, distribuía tareas, exponía su opinión como la única, o había quien solicitara frecuente aprobación del asesor de práctica respecto a la marcha y los resultados parciales del trabajo. Se presentó el caso de estudiantes que asumieron autoridad ante los otros para exigir la realización de tareas o el cumplimiento de compromisos. El trabajo colaborativo tiene entre sus raíces los aportes que hace el constructivismo sociocultural a la educación, pues la superación de la idea de aprender-qué- hacia la forma-cómo- procede a la construcción de redes, hoy, características y determinantes de los entornos -dónde-. En consecuencia, desde cualquier espacio o lugar, varias personas pueden enriquecer o aportar a la producción y a los productos que lograría una sola.

Se parte del constructivismo, afirmando que los estudiantes protagonizan el aprendizaje, construyen su conocimiento a partir de sus pensamientos y experiencias, los cuales son básicos para potenciar la imaginación, la creatividad y familiarizar nueva información. Coll afirma (2006) que corresponde al docente atender las inquietudes y solicitudes de los estudiantes de manera respetuosa y plantearle desafíos que puedan afrontar y superar para que conserven o incrementen sus motivaciones y reafirmen su valor y estima.

Siguiendo al autor, la reflexión, el análisis y el cuestionamiento del ejercicio expositivo del docente, de su práctica falta de crítica, poco reflexionada, con vacíos en su fundamentación y afrontada a la urgencia y necesidad de aprendizajes significativos por parte de los estudiantes, fueron el preámbulo para la didáctica mencionada. La confrontación realidad-ideal de la formación profesional y humana llevó a los asesores de práctica y a los estudiantes de Licenciatura al diseño de interacciones pedagógicas ${ }^{5}$ enfáticas en el protagonismo de los estudiantes, tendientes al desarrollo, la formación y la producción individual unida al compromiso y la responsabilidad en el trabajo conjunto. Inició un proceso de redimensión y resignificación del quehacer educativo.

Nombre atribuido a las sesiones de trabajo diseñadas por los estudiantes de Licenciatura, en las cuales procuraban el protagonismo de los estudiantes de los ciclos de básica y aprovechaban las experiencias cotidianas dentro del aula para la reflexión. 
La importancia de comprender, asumir y afrontar la práctica movilizó aspectos de la formación integral, hizo coincidir un elemento antecedente y otro de desarrollo. El primero fue entender, de la práctica, su intención explícita de formación, caracterizada por la puesta en escena de cada estudiante con sus herramientas multidimensionales; el segundo fue leer, interpretar e interrogar la realidad del aula y emprender acciones de transformación. Ambos asuntos redundaron en la importancia de utilizar estrategias que aportaran a los estudiantes en ciclos de básica una significación real y potencial de los conocimientos adquiridos en la escuela y por otra parte, llevaron a discusiones y acuerdos para realizar el trabajo.

La reflexión, criticidad, indagación y búsqueda de alternativas durante el proceso, muestran cómo la investigación-acción y el trabajo colaborativo implican el apoyo moral para mejorar la comprensión y el rendimiento, con sustento en el contexto y en un currículo de proceso, promueven el análisis de la práctica profesional a partir de la ética, la estética, la relación valoresconocimientos y el dominio pedagógico y disciplinar según el sistema curricular; estima los espacios escolares para deliberar y tomar decisiones que mueven a la colaboración, integran las experiencias extraescolares y mantienen un discurso de investigación-acción para mejorar la comprensión y los problemas prácticos del currículo Elliott (2000); Sacristán (2002); Mckernan (1999).

Durante la práctica investigativa, en las sesiones de seminario ${ }^{6}$ fueron implementadas estrategias como la comunidad de indagación, la indagación crítica analógica, el eje de creación libre, los debates entre equipos ${ }^{7}$, la $\mathrm{V}$ heurística y los mapas conceptuales. El trabajo virtual se centró en la comunicación por correo y el foro. La planificación de interacciones pedagógicas por parte de los docentes en profesionalización privilegió el proyecto de aula, el aprendizaje basado en problemas y el taller reflexivo.

La comunidad de indagación, la anticipación crítica analógica, el eje de creación libre y los debates entre equipos, propiciaron la apertura de los estudiantes a la apreciación de diferentes puntos de vista, la flexibilidad respecto a distintos rasgos sociales y culturales y la realimentación de particularidades de aula; también aportaron a la capacidad de exponer ante el grupo.

La V heurística y el mapa conceptual, con las anteriores, favorecieron la apropiación de herramientas para formular preguntas, el establecimiento de conexiones, la consideración de niveles de amplitud y profundidad, la realización de análisis y síntesis. Empezaron a: estructurar ideas antes de plasmarlas en el escrito, conjeturar con base en sus marcos contextuales para acercarse a otros conocimientos y buscar sustentos teóricos para explicar actitudes, disposiciones y comportamientos de los estudiantes en los ciclos de básica. Sus conversaciones reflejaban paulatino reconocimiento respecto a qué sabían, qué debían averiguar o qué requería modificación para resolver la situación pedagógica en cada CER o IER.

Aportaron también a identificar errores de entendimiento y comprensión, superar la búsqueda de regulación, control y veeduría externa, dar cabida a las discusiones argumentadas, el disenso y las producciones. Las dinámicas de trabajo se tornaron en relaciones

\footnotetext{
6 Los encuentros con los estudiantes de Licenciatura se dieron en tres modalidades: presencial (seminario de fundamentación) asesoría y acompañamiento presencial y asesoría y acompañamiento virtual; todos concurren en el término encuentro.

7 Estrategias tomadas de la propuesta de pensamiento de alto orden, llevada a cabo por Ovidio D'angelo y América Valdés, cubanos.
} 
simétricas haciendo poco diferenciable el rol de estudiantes y de docentes, enfáticas en el carácter humano, la disposición y actitud para aprender continuamente.

El trabajo colaborativo como didáctica, parte de considerar a cada persona en una perspectiva de responsabilidades, con derechos y deberes, que le permiten reflexionar-se, exponer-se, situar-se y dimensionar-se o redimensionar-se frente al devenir, cuestión en que las posturas éticas y morales están mediadas por la palabra argumentada, la capacidad de negociar y de explicar-se en contextos dialécticos y dialógicos, que connotan en las relaciones un carácter discursivo, coherentes con los giros socioeducativos, culturales y lingüísticos para la transformación social y la intersujeción, sinónimo del reconocimiento de interdependencias.

En esta didáctica convergen intenciones de un grupo de estudiantes para alcanzar propósitos comunes que ameritan la utilización de herramientas metodológicas y tecnológicas para buscar y llevar a cabo la intención de trabajo con optimización del tiempo, circulación de la información, acceso a los medios, los instrumentos de trabajo y los espacios, elevando los niveles de productividad y sus resultados. Implementar el trabajo colaborativo exige tener presentes los actores, los entornos, los recursos y las funciones.

Los actores son las personas que participan protagónicamente en el acto pedagógico, en este caso se destaca a los estudiantes en profesionalización al interior de sus comunidades, ubicadas en zonas con singularidades geopolíticas, culturales y económicas que determinan proximidad o distancia de otros lugares rurales y de las características del sector urbano en general.
Los entornos son los espacios físicos, históricos, culturales y geográficos en los cuales convergen los actores con las situaciones, experiencias de vida y asuntos, que de manera continua, se constituyen en sus temas de conversación, tensión y perspectiva, derivando en contenidos de carácter social y cognoscitivo.

Con los recursos se alude a dos cuestiones. En primer lugar, las habilidades, las capacidades, las destrezas y los conocimientos que poseen las personas, presentes en las dimensiones humanas e influyentes en la efectividad de las interacciones con diferentes grupos, y en segundo término, a los materiales que provee el medio, que existen allí o son adquiribles en otros entornos. Las funciones, con las responsabilidades y los cargos que al interior de los grupos asumen las personas, provienen de los intereses y las motivaciones existentes en quienes se erigen como grupo de trabajo colaborativo, y de las interrelaciones que allí se expresan, diferenciando unos grupos de otros.

La conformación de grupos para este tipo de trabajo requiere la apropiación tecnológica para movilizar las herramientas cognitivas, los recursos, los contenidos y los entornos, disminuir los efectos de las distancias geográficas y atenuar las desigualdades sociales. Los intereses y propósitos del grupo son comunes, acordes con las capacidades, las facultades, el tiempo y los recursos de sus integrantes, quienes asumen funciones, responsabilidades y roles, constituyéndose en una 'organización' singular y autónoma, con frecuencia favorecedora de la expresión individual, la productividad y los productos.

En la conjugación investigación-acción-trabajo colaborativo, son cualidades el énfasis en procesos 
y procedimientos realizados por los estudiantes para aprender, las discusiones y divergencias, la constante búsqueda de razones para sostener opiniones, el reconocimiento de fortalezas en cada integrante del grupo, la confianza en los aportes del otro, el sentido de paridad, la consciencia respecto a la consecuencias de las decisiones y los actos. Se logra mirar una misma situación desde ángulos distintos y como docentes, se marcha en búsqueda de equilibrio entre soportes teóricos, actitudes, procedimientos y habilidades para cualificar el desempeño.

De esta investigación se obtienen los conceptos que se presentan a continuación.

\section{Didáctica}

En las perspectivas didácticas de hoy, el significado de autoridad está dado por el paso de relaciones verticales entre docentes y estudiantes hacia la búsqueda de simetría. Sin establecer rivalidades, docentes y estudiantes afrontan situaciones deliberativas en las que, cede la distancia entre el gobernante o docente impositivo y los gobernados o estudiantes pasivos, para dar paso al consenso, en tanto docentes y estudiantes son seres humanos con potencialidades por desarrollar o fortalecer, necesidades para solventar, oportunidades para actuar y capacidad humanamente perfectible.

La nueva forma de asumir la autoridad es consonante con el pluralismo: considera diferencias individuales, posturas ideológicas y políticas, concurrencia de disciplinas, reconocimiento de agentes y contenidos culturales socializantes, identificación de entornos educativos, aporte de disciplinas a la construcción de un mismo asunto. En tal sentido, cambia el prestigio del docente como autoridad
“(...) no es que el profesorado deje de enseñar, sino que también puede ser cuestionado, deja de ser el poseedor de la verdad absoluta (...) el diálogo se configura como esencial respondiendo a la demanda que desde la sociedad se articula (...)" (Elboj, Puijdellivol y otros; 2004: 26).

La autoridad es un componente clave de la didáctica que se gana por el respeto entre las partes cuando al dialogar exponen sus puntos de vista, argumentan y consensúan; en síntesis, “(...) es un acto de comunicación entre el docente y los alumnos. Aquél el elabora un mensaje que debe ser comprendido por sus receptores; algo para lo cual, como lo establece la teoría de la comunicación, es menester que el mensaje sea dado significativamente en el mismo campo de experiencias que dominan los alumnos" (Gallego Badillo; 2001: 20).

El respeto emanado y consolidado a partir del acto comunicativo está mediado por la investigación pues "difícilmente tenemos la posibilidad, la disponibilidad o la prioridad de investigar sobre nuestras maneras de enseñar. Se prioriza la investigación sobre la materia curricular por encima de la investigación de la propia función pedagógica, lo cual conlleva a un desencuentro cada vez más grande entre el saber que se aprende y el saber que se enseña" (Bautista, Borges y Forés; 2006: 60).

En la estructura física como relacional los encuentros de estudiantes y docentes presentan cambios, sin embargo, requieren mayor reflexión y criticidad para avanzar hacia propuestas que enriquezcan el aprendizaje. Entre los aspectos por trascender, unido a la prospectiva de formación humana y a la concepción de currículo, está el aula, espacio clásico, todavía concebido para impartir, conservar y reproducir el orden social, para garantizar la producción de seres 
homogéneos en contextos y condiciones sociales distintas a través de acciones disciplinarias, la regulación y el control.

Los giros en la historia presentan cambios en la didáctica "(...) la acción comunitaria pasaría por la colaboración con el entorno, a través de personas y entidades, en la consecución de los objetivos de la escuela; es decir, la formación de futuros ciudadanos útiles a sí mismos y a la sociedad (...) Actualmente no se concibe una escuela carente de relaciones con el territorio; es impensable. De hecho, el aspecto sociocultural y la procedencia de los alumnos marca la escuela y la respuesta que los profesionales de la educación tenemos la obligación de dar. Así pues el entorno escolar es el eje básico que guiará la acción comunitaria en la educación escolar" (Taranilla; 2006: 114)

Hoy el aula se abre a los entornos educativos identificados en/desde la comunidad, asumida en espacios reales y virtuales que hacen coincidente la educación en las finalidades y la contextualización: se buscan alternativas para facilitar procesos de aprendizaje, los fines no cambian y los actores del proceso educativo restan cada vez más diferencias respecto al tipo de relaciones establecidas por cuanto les asiste el mismo ánimo. Es clave en las didácticas de hoy, la autoridad.

\section{Autoridad}

En perspectiva de los grupos de trabajo colaborativo, las comunidades de aprendizaje o las redes, la autoridad trasciende el género, la edad, la profesión para dar curso a la construcción de la autonomía y al agenciamiento de la libertad, con base en la responsabilidad como medio y fin de la construcción humana y social. La autoridad es edificada en interdependencia con las personas al tiempo que resalta la singularidad y autenticidad, generadora de diferencias y similitudes cuyo sustento son las potencialidades y su despliegue al interior del grupo, la comunidad y el entorno.

La autoridad empieza con la capacidad de gobernarse y expresarse, proceso que resulta particular en los primeros años del ciclo vital cuando los vínculos con agentes y elementos socializantes influyen y hasta llegan a determinar la capacidad de situarse ante sí y de decidir, la posibilidad de explorar el mundo a partir de los valores establecidos y aceptados por la sociedad, el conocimiento de los bienes y propiedades de los otros así como la aceptación de diversos puntos de vista. Asimismo se asienta en principios éticos y morales que orientan el respeto y la correspondencia con los otros y con los preceptos establecidos o acordados para la convivencia.

Puede afirmarse que cada persona en su interior realiza diligencias para elegir cómo obrar y decidir, si delega o no determinados asuntos. Esos rasgos anuncian la libertad en unos parámetros de unión, dados por la concordia con otros o conforme a las normas de comportamiento y convivencia, y la separación, entendida como la distancia o el aislamiento respecto a ideas o posturas en principio, iguales o similares, propias para la determinación y la autodeterminación. El vínculo entre autoridad y libertad es la responsabilidad, materializada en asumir las consecuencias de las decisiones, los juicios y las acciones.

Estas características armonizan en la autonomía, pues “(...) altos niveles de libertad y autonomía exigen altos niveles de responsabilidad para los cuales hay que preparar a la generación futura; ya que como decía Aristóteles, la libertad me permite decidir cómo, cuándo y hacia dónde-si 
así lo decido- envío una piedra, pero una vez lanzada, ya no soy libre de volver a decidir" (De Zubiría; 2003: 124).

Sin que sea condición, el cooperativismo traducido en dependencia y fragmentación del trabajo anuncia escasos o nulos niveles de libertad y responsabilidad, asunto que indica la importancia de pensar y hacer una escuela autónoma para el propósito fundamental de la formación; una escuela autónoma, que ilumine el camino a seguir y provoque en los estudiantes el deseo de ser y saber por sí mismos, capacitados para discernir y elegir el tipo de información y de conocimientos requeridos para sacar adelante sus propósitos.

\section{Metodología de trabajo}

Los roles asumidos por estudiantes y docentes en el grupo de trabajo colaborativo generan o consolidan vínculos distintos en cada persona consigo misma, con las otras, con los conocimientos, la ciencia, los artefactos tecnológicos y la consciencia social. Sin lugar a dudas, teoría y práctica se funden para hablar de personas prácticas en tanto los elementos prescritos que perennizan la observación, característica de estudiantes pasivos, son movidos por las interpretaciones y comprensiones propias derivadas de la reflexión y criticidad de diferentes textos.

Las maneras de organizar o disponer los espacios y recursos para propiciar el aprendizaje tienen asidero en fundamentos que superan contenidos prácticos, pues se erigen en procedimientos para acercarse a las metas de formación autónoma. Es así que a partir de la experiencia cabe destacar en las interacciones pedagógicas, sus contribuciones a la edificación humana y social, asentada en procesos analíticos, conceptuales, conectivos y de síntesis que son individuales. Son estos los que alientan la identificación de los criterios que a continuación se exponen en dicho trabajo:

- La responsabilidad: La aceptación de distintos puntos de vista pasa por el deber de argumentar bajo unos principios de ética y moral y el derecho a disentir; así, las discusiones, disensiones o conflictos son llevados a la reflexión y criticidad. Por otra parte, cada persona asume el compromiso de su desempeño dentro del grupo.

- La cooperación: El aporte individual implica asumir la tarea completa, esa es una muestra de que se comparten intenciones e intereses del grupo que paulatinamente generan o consolidan interdependencias.

- El liderazgo: Las singularidades humanas se expresan de manera distinta, a partir de la superioridad o el dominio en ciertas dimensiones, fortalezas, capacidades o cualidades, encaminados a atender la solución de situaciones comunes. En lugar de un líder por un grupo de trabajo colaborativo, dentro del grupo el tipo de relaciones establecidas potencia el liderazgo de cada integrante.

- La autoridad: Coexisten actitudes de simetría, horizontalidad e igualdad que armonizan los comportamientos sociales y afectivos del grupo con dominios temáticos, teóricos o conceptuales que movilizan e iluminan los procesos de búsqueda y modificación de situaciones. Esto permite identificar oportunidades que promueven el consenso en lugar de la instrucción y la institución de relaciones verticales.

- El aprendizaje: Son reconocidas, adoptadas, transformadas o establecidas estrategias y técnicas que promueven la autodisciplina y la autorregulación. La conjugación de 
saberes culturales, conocimientos escolares y las experiencias, son nodales para aprender.

- Consenso: Consecuente con posturas distintas y diferentes formas de abordar los asuntos, se presentan discusiones y opiniones que tensionan las relaciones de grupo, es cuando los acuerdos entre las partes hacen inminentes las posturas éticas y las construcciones académicas para que prosiga la marcha de los procesos.

- El diálogo: En lugar de relaciones verticales, las partes con sus posturas y argumentos, deliberan hasta reconocer diferencias y discursos, plantear alternativas y llegar a acuerdos.

La concreción de estos fundamentos tiene como eje el diálogo en contexto.

\section{Producción textual}

\section{Teetetes: ¿Qué entiendes por pensar?}

Sócrates: Un discurso que el alma se dirige

a si misma sobre los objetos que considera.

\section{Me explico como un hombre}

que no sabe muy bien aquello que habla,

pero me parece que el alma, cuando piensa,

no hace otra cosa que conversar consigo misma,

interrogando y respondiendo, afirmando y negando,

y que cuando se ha resuelto, ser más o menos pronto

$y$ ha dicho su pensamiento sobre un objeto

sin permanecer más en duda, en esto consiste el juicio.

Asi pues, juzgar, es mi concepto, es hablar,

y la opinión es un discurso pronunciado, no a otro,

ni de viva voz, sino en silencio y a sí mismo.

¿Qué dices tú? Platón, Teetetes
Los discursos de la sociedad son dirigidos a las personas a través de grupos con diferentes edades, pares, medios de comunicación y de información; se van legando entre generaciones y se valen de tradiciones, costumbres y artefactos para ponerlos a circular. Desde ahí empieza la formación de una consciencia colectiva que crece y se afianza hasta establecer rasgos personales pero comunes a la colectividad. Y es esa colectividad la que orienta, edifica, conserva o modifica el pensamiento según las experiencias de vida y las situaciones que van haciendo la singularidad de cada quien.

El razonamiento sobre cuanto se siente o se piensa alienta aquello que se expone ante otros y orienta la selección de palabras y frases buscando la mejor manera de hacerlo. Aquí tienen cabida las conjeturas, discusiones y prácticas llevadas a cabo por los estudiantes de Licenciatura, exteriorizadas en conversaciones, matizadas en un principio por vacíos de concepción metodológica en el trabajo con estudiantes de Centros Educativos Rurales -CER-e -Instituciones Educativas Rurales-, empezadas a superar por la puesta en acción del pensamiento, alimentadas por las reflexiones, discusiones y los registros en los diarios diligenciados.

Las inquietudes respecto a los procesos de lectura y escritura de los estudiantes de educación básica en los entornos rurales permiten identificar en los procesos y el desarrollo de pensamiento el aprendizaje como asunto prioritario, encontrar en las conversaciones y en los diálogos de grupo de trabajo colaborativo, elementos para cuestionar los discursos docentes como unidades de texto poco provistas de fundamentos críticos y de carácter propositivo.

Las correlaciones discurso docente-aprendizaje de los estudiantes son reflejadas en los desempeños 
de los estudiantes: las formas de hablar, expresar, escribir junto con lo que se expresa, son acciones frecuentemente tomadas por los estudiantes. En tal sentido el texto como unidad de lenguaje, al hablarse, escribirse o leerse presenta modificaciones acordes con el contexto, pues "el nivel semántico es el significado, que no puede ser otra cosa que significado en contextos de situación, esto es, significado en uso" (Gil; 2001: 172).

\section{Trabajo colaborativo}

Conformar grupos de trabajo colaborativo es un paso para congregarse en redes y comunidades de aprendizaje, a partir de las cuales emergen nuevos significados referidos a autoridad, economía de recursos, nexos humanos, sociales y académicos, acceso a herramientas virtuales, y especialmente, a una visión integral e integradora del ser humano en contexto. Las redes desde el punto de vista curricular, demandan la consideración del pasado para actuar sin lesionar las tradiciones de las personas, ameritan situarse en el presente con las tensiones y sistemas complejos que le caracterizan y considerar en prospectiva el desarrollo de las personas en condiciones de igualdad.

Los grupos colaborativos tienden a transformarse en redes cuando fruto de su proceso formativo se sumergen en la autocriticidad de sus acciones y sus discursos, llegando al cuestionamiento de sus prácticas cotidianas que les hace mirar otros horizontes, diferentes realidades. Situación comparable con un alimento que nutre pero no sacia. De ese modo, el día a día está pleno de reflexiones ineludibles para asentar postura crítica frente al quehacer en el CER o la IER y redimensionar la responsabilidad social, profesional y humana. Se protagoniza, aunque quizá de manera inconsciente, la construcción del currículo de la vida humana y de la institución como experiencia de acción y transformación.

En esta didáctica, la relación enseñanzaaprendizaje presenta cambios, asistidos por lógicas contextuales e históricas. La autoridad del docente ha cambiado: el pluralismo cultural como la vivencia de conflictos en el sector rural, amerita el diálogo, la exposición y comprensión de razones, que en lugar de contraponerse deriven en la negociación con los estudiantes y demás grupos sociales comprometidos o involucrados; los esquemas y las ideas de trabajo centradas en creencias, faltas de sustento epistemológico están cuestionados y la clasificación, comparación y jerarquización de estudiantes está desdibujada, pues en su lugar, surgen y se consolidan líderes en diferentes dimensiones aspectos.

Desde una mirada histórica, los giros del trabajo colaborativo en la historia enfatizan hoy en quien estudia o en quien aprende. En tal sentido, según la RAE, estudiante es "que estudia. Persona que cursa estudios en un establecimiento de enseñanza" mientras el aprendiz es la "persona que aprende algún arte y oficio. Persona que, a efectos laborales, se halla en el primer grado de una profesión manual, antes de pasar a oficial”. Estas diferencias sugieren la discusión respecto al carácter profesional de la formación en el sistema colombiano.

\section{Resultados}

El predominio de metodologías pasivas con estudiantes de básica primaria en Escuela Nueva, fue el detonante para que los estudiantes de Licenciatura reflexionaran respecto a situaciones hasta entonces señaladas por ellos como problemas o desmotivación para aprender los contenidos de las diferentes áreas. Fueron testimoniados vacíos en las bases epistemológicas 
que derivaron en la realización de planes individuales de mejoramiento, acompañados por los asesores de práctica.

El autorreconocimiento fue un aprendizaje que partió de la confrontación de grupo y de proveer herramientas para la autoconfrontación entre la sujeción a las normas y directrices de los docentes y la independencia como sinónimo de crecimiento personal, saber profesional y valor propio. Poner en palabras el sentir afloró temores e inseguridades, inhibidores de la palabra para la visiblización y del argumento para el disenso.

Con los estudiantes de Licenciatura la participación pasó de una posibilidad y asunto previsto desde afuera -por el docente- a convertirse en criterio de trabajo de las estrategias aplicadas para aproximar a la didáctica de trabajo colaborativo. El establecimiento de acuerdos para el trabajo y de indicadores que evidenciaran conocimiento, procedimientos y productos, tensionaron hasta el punto de llevar a la confrontación, el autocuestionamiento, y luego, a la modificación de prácticas con los estudiantes de básica en los CER y las IER.

En las acciones realizadas por los estudiantes de Licenciatura se fundieron el asunto investigado -lectura y escritura de los estudiantes de básica- y el fortalecimiento de habilidades personales -lectura y escritura de los docentes en profesionalización-. Aquí se evidencian rasgos evaluativos en los docentes de educación básica con relación a su formación y su saber, al contexto y a los propósitos de la Licenciatura. Simultáneamente, fusionaron docencia e investigación con orientación al aprendizaje de los estudiantes, en un marco de valores y habilidades movilizado por el grupo de trabajo puesto a su servicio.
Las discusiones y confrontaciones entre miembros de los grupos tuvieron como escenario las realidades de aula, los encuentros en las veredas, los espacios de discusión dentro de los seminarios de práctica y los encuentros a través de herramientas informáticas. Uno de sus principales aportes fue la identificación de vacíos en el conocimiento, el paso de posturas pasivas centradas en la observación a la criticidad y el abordaje de contenidos, conceptos y teorías en una perspectiva dialogal.

El trabajo colaborativo dentro de la práctica investigativa contribuyó al desarrollo de habilidades para reflexionar, indagar, ejemplificar, comparar, disentir, hacer conexiones, argumentar, describir, comunicar; así se reflejó en la planificación de interacciones pedagógicas y los registros que daban cuenta del desarrollo de las mismas con los estudiantes de básica. Fue un elemento que evidenció momentos de autonomía relacionados con el autogobierno de sus propósitos y tareas.

\section{Conclusiones}

Transformar la educación empieza por reconocer los valores sociales, culturales y políticos que determinan la vida personal, el tipo de relaciones que se establecen con los otros, con el aprendizaje y el conocimiento. Es prioritario disponer los recursos cognoscitivos y tecnológicos para que los estudiantes desplieguen las habilidades y la responsabilidad, requeridas en el proceso de aprender y conocer a la vez que se construyen a sí mismos.

Aprender y conocer son acciones centradas en motivaciones personales que invitan a situarse en el contexto, a sentirse y saberse parte de distintas comunidades que requieren de manera simultánea funciones, roles y desempeños diferentes. Aquí 
radica la importancia de didácticas centradas en aprendizajes en lugar de conocimientos, de desplegar la comunicación como acto de formación que supera la información y de participar en las normas y reglas de convivencia de la comunidad para su transformación.

Los vínculos investigación-educación-entorno, en lugar de necios debates o invenciones, requieren actitudes de vida y aptitudes mentales de docentes, personas y agentes comprometidos, que encaminen a considerar el ser humano, el proceso educativo, la comunidad... cada uno como un todo, como unidad, y a identificar al mismo tiempo la singularidad de sus componentes. Lograrlo amerita por parte de los docentes el trabajo mancomunado con otros agentes y sectores de la sociedad al igual que la clarificación de principios orientadores de los niveles de concreción.

El ejercicio llevado a cabo por los estudiantes de Licenciatura se tradujo en disposiciones distintas de los estudiantes de CER e IER hacia la lectura y la escritura; las principales elaboraciones de textos orales fueron alrededor de anécdotas, situaciones de la vida cotidiana y recreación de cuentos; hubo quienes se atrevieron a escribir poesías, adivinanzas y cuentos. Entre los docentes sus registros de práctica mostraron madurez en cuanto a la correlación de ideas y la ganancia de fluidez.

Si bien la educación es considerada una estrategia para el desarrollo de las personas, la educación en sí misma presenta aspectos críticos, entre ellos las díadas cobertura-calidad, modernidadmodernización, expresada esta última en la disposición de herramientas tecnológicas y la insuficiente apropiación de las mismas.
La importancia de los docentes como referentes para los estudiantes tiene entre sus fundamentos lo que estos últimos saben pero también lo que son, así se desprende de la apropiación del discurso logrado por los estudiantes de Licenciatura, la cual desató en los estudiantes de básica de los CER y las IER otras miradas hacia los encuentros con el conocimiento y captó el interés hacia determinado tipo de textos.

La formación en la responsabilidad y la autonomía impactan, abriéndose a otras oportunidades sociales, así se desprende de dos estudiantes de Licenciatura que una vez graduados, han sido promovidos por autoridades educativas locales como asesores para orientar el trabajo de investigación con docentes de sus veredas, en microcentros, y un tercer estudiante promovido a Director de núcleo educativo.

\section{Discusiones}

Una de las condiciones para extender el trabajo colaborativo y las redes derivadas del mismo, es el acceso a TIC, sin embargo, aproximadamente un $33.3 \%$ de los 48 estudiantes que participaron de la investigación no tienen en sus veredas servicio de electricidad. En contraposición, se cuenta con recursos del entorno utilizados instrumentalmente, en tanto no se recurre al diálogo como posibilidad para explorarlos o aprovecharlos para propuestas de transformación del trabajo escolar.

El trabajo colaborativo, en perspectiva filosófica, amerita el establecimiento de comunidades y redes de aprendizaje que sean extensibles al sector productivo y económico de los entornos rurales, de otro modo, resulta difícil disminuir las brechas para que las personas se acerquen a la información, la comunicación y el conocimiento. 
El compromiso educativo y social de los docentes requiere pasar del énfasis en la instrucción de estudiantes al tejido de estructuras en los mismos; aquí la importancia de hacer lectura crítica de la realidad de grupo, comunidad, entorno y currículo en perspectiva de indagación, confrontación y argumentación continua, por parte de quien aprende.

La formación profesional resulta insuficiente para garantizar procesos de calidad educativa, por tanto, se precisa la instauración de redes y comunidades de trabajo colaborativo como alternativa para hacer de la criticidad y proposición dos constantes con relación a los currículos y sus influencias en el aprendizaje y el desarrollo de las personas.

El trabajo educativo de los docentes en el sector rural está caracterizado por la existencia de vínculos docencia-administración-investigación; este último aspecto requiere la materialización de políticas estatales para su desarrollo y sostenimiento.

Dado que la investigación no es particular de personas, áreas de conocimiento, instituciones o instancias, su práctica debe ser promovida a lo largo de la formación para integrar conocimientos, saberes, regiones, naciones... y debe hacer del conocimiento un asunto público mediado por la participación como cuestión de igualdad.

Si bien el trabajo colaborativo en principio es una opción en tanto el aprendizaje finalmente es responsabilidad de cada persona, genera inquietud que haya quienes experimenten $y$ expresen desidia para unirse con otras personas, grupos o redes, aludiendo las preferencias individuales. 


\section{Bibliografía}

Albert Gómez, María José. (2006). La investigación educativa, claves teóricas. España. Mc Graw Hill.

Bautista Guillermo, Federico Borges y Ana Forés. (2006). Didáctica universitaria en entornos virtuales de enseñanza-aprendizaje. Narcea

Carr Wilfred. (1998). Teoría crítica de la enseñanza. España. Morata.

Coll C., Martín E., Mauri T., Miras M.y otros. (1997). El constructivismo en el aula. Graó.

De Zubiria Samper Julián. (2003). De la escuela nueva al constructivismo, una análisis crítico. Bogotá. Aula abierta Magisterio.

Diccionario de la Real Academia de la Lengua Española. (2001), s.e.

Elboj Carmen, Puijdellivol Ignasi, Soler Gallart Marta y Valls Rosa. (2004). Comunidades de aprendizaje: Transformar la educación. Graó. España

Elliott John. (2000). La investigación-acción en educación. Morata. España
Elliott John. (2000). El cambio educativo desde la investigación-acción. Morata. España

Gallego-Badillo Rómulo. (2001). Saber pedagógico. Cooperativa editorial Magisterio. Bogotá.

Gil José María. (2001). Introducción a las teorías lingüísticas del siglo $\mathrm{XX}$.

Latorre Antonio. (2003). La investigaciónacción, conocer y cambiar la práctica educativa. Graó. España.

McKernan. P. James. (1999). Investigaciónacción y currículo. Morata España.

Pérez de Cabaní María Luisa, Pérez María L. Barberá Elena. (1997). Cuadernos de análisis: La enseńanza y aprendizaje de estrategias desde el currículum. Universitat de Girona.

Sacristán J. Gimeno. (2002). El currículum: una reflexión sobre la práctica. Morata. España

Taranilla María del Carmen (2006). En Miradas y diálogos en torno a la acción comunitaria. Graó. España. 